\title{
Analisis Klasifikasi Kelahiran Caesar Menggunakan Algoritma Naïve Bayes
}

\author{
Ginanjar Abdurrahman ${ }^{1}$, Johan Taruna Wijaya ${ }^{2}$ \\ Program studi teknik informatika, Fakultas Teknik Universitas Muhammadiyah Jember \\ Email: ${ }^{1} a b d u r r a h m a n g i n a n j a r @ u n m u h j e m b e r . a c . i d,{ }^{2}$ johantaruna007@gmail.ac.id
}

(Naskah masuk: 24 Juni 2019, diterima untuk diterbitkan: 5 Juli 2019)

\begin{abstract}
ABSTRAK
Angka kematian Ibu (AKI) merupakan jumlah kematian ibu selama masa kehamilan hingga pasca melahirkan yang disebabkan kehamilan, persalinan atau pengelolaannya dan tidak disebabkan kecelakaan di setiap 100.000 kelahiran hidup. Kelahiran Caesar adalah alternatif terakhir dalam persalinan, dikarenakan faktor resiko yang tinggi. Walaupun resikonya tinggi, angka kelahiran Caesar mengalami peningkatan signifikan, khususnya di Indonesia. WHO menetapkan standar persalinan Caesar suatu negara berkisar 5-15 persen per seribu kelahiran di dunia. Machine learning merupakan cara mesin belajar dari data. Terdapat beberapa aplikasi machine learning yang telah dikembangkan. Salah satunya adalah machine learning WEKA. Weka merupakan software untuk data mining yang dilengkapi dengan algoritma standar machine learning termasuk klasifikasi. Pada penelitian ini dilakukan klasifikasi kelahiran Caesar menggunakan algoritma Naïve Bayes untuk menentukan apakah kelahiran akan diberikan tindakan operasi Caesar atau melahirkan secara normal. Dataset yang digunakan terdiri dari 80 data ibu hamil dengan 5 atribut, yakni: umur, jumlah tenaga medis, waktu melahirkan, tekanan darah, masalah hati. Hasil penelitian ini diharapkan dapat membantu dunia kesehatan khusunya untuk menentukan proses kelahiran perlu diberi tindakan operasi Caesar ataukah tidak dengan menyediakan model klasifikasi untuk melakukan prediksi secara medis. Hasil dari penelitian ini diharapkan dapat menunjang dunia kesehatan khususnya pada kasus ibu melahirkan dengan menyediakan model klasifikasi yang dapat digunakan untuk melakukan prediksi maupun pengambilan keputusan medis lainnya.
\end{abstract}

Kata kunci: Kelahiran, Caesar, Klasifikasi, Naïve Bayes, Weka

\begin{abstract}
Maternal mortality rate (MMR) is the number of maternal deaths during pregnancy to postpartum caused by pregnancy, childbirth or its management and is not caused by accident in every 100,000 live births. Caesarean birth is the last alternative in labor, due to high risk factors. Despite the high risk, the Caesar birth rate has increased significantly, especially in Indonesia. WHO set a country's Caesar labor standards ranging from 5-15 percent per thousand births in the world. Machine learning is a way of machine learning from data. There are several machine learning applications that have been developed. One of them is WEKA machine learning. Weka is a data mining software that is equipped with standard machine learning algorithms, including classification,. In this study the classification of Caesarean births was performed using the Naïve Bayes algorithm to determine whether the birth would be given a Caesarean section or a normal delivery. The dataset used consisted of 80 data on pregnant women with 5 attributes, namely: age, number of medical personnel, time of delivery, blood pressure, liver problems. The results of this study are expected to help the world of health, especially to determine the birth process needs to be given a Caesarean or not by providing a classification model for medical predictions. The results of this study are expected to support the world of health, especially in the case of mothers giving birth by providing a classification model that can be used to make predictions and other medical decision-making
\end{abstract}

(Keywords: Birth, Cesarian, Classification, Naïve Bayes, Weka 


\section{PENDAHULUAN}

Angka kematian lbu (AKI) di Indonesia masih tinggi. AKI merupakan jumlah kematian ibu selama masa kehamilan hingga masa pasca melahirkan yang disebabkan oleh kehamilan, persalinan dan nifas atau pengelolaannya dan tidak disebabkan karena kecelakaan atau terjatuh di setiap 100.000 kelahiran hidup (Kemenkes, 2017).

Kelahiran secara Caesar merupakan alternatif terakhir dalam tindakan persalinan. Hal ini dikarenakan faktor resiko yang tinggi, baik resiko bagi ibu maupun bayi (Onggang dalam (Anggorowati \& Sudiharjani, 2010). Walaupun resikonya tinggi, angka kelahiran secara Caesar mengalami peningkatan secara signifikan, khususnya di Indonesia (Andayasari et al., 2015). World Health Organization (WHO) menetapkan standar persalinan operasi Caesar di suatu negara sekitar 5-15 persen per seribu kelahiran di dunia (Sihombing, Saptarini, \& Putri, 2010). Berdasarkan data WHO (Dalam (Andayasari et al., 2015)), pada tahun 2004-2008 di tiga benua (Amerika latin, Afrika dan Asia) angka kelahiran Caesar terendah adalah di Angola (2,3\%) dan tertinggi di Cina $(46,2 \%)$. Data kelahiran Caesar di Indonesia meningkat tajam, khususnya di kota-kota besar. Berdasarkan data Riskedas (2010) dalam Andayasari (2015:106) kelahiran Caesar sebanyak $15,3 \%$. Angka terendah di Sulawesi Tenggara $(5,5 \%)$ dan tertinggi di DKI Jakarta $(27,2 \%)$

Machine learning mempelajari cara mesin untuk belajar dari pengalaman atau cara memprogam mesin untuk dapat belajar. Machine learning diistilahkan dengan learn from data, kerena membutuhkan data untuk belajar (Alpaydin dalam (Lukman \& Marwana, 2015)). Terdapat beberapa aplikasi machine learning yang telah dikembangkan. Salah satu adalah machine learning WEKA (Waikato Environment for Knowledge Analysis). Weka merupakan software untuk data mining yang dilengkapi dengan algoritma standar machine learning, diantaranya algoritma preprocessing, klasifikasi, clustering, regresi, asosiasi, dan visualisasi (Lukman \& Marwana, 2015)

Pada penelitian ini dilakukan klasifikasi kelahiran Caesar dengan mengaplikasikan algoritma Naïve Bayes untuk menentukan apakah kelahiran akan diberikan tindakan operasi Caesar atau melahirkan secara normal (Tidak Caesar). Dataset yang digunakan terdiri dari 80 data ibu hamil dengan 5 atribut, yakni: umur, jumlah tenaga medis, waktu melahirkan, tekanan darah, masalah hati. Hasil penelitian ini diharapkan dapat membantu dunia kesehatan khusunya untuk menentukan proses kelahiran perlu diberi tindakan operasi Caesar ataukah tidak dengan menyediakan model klasifikasi untuk melakukan prediksi secara medis.

\section{METODE PENELITIAN}

\section{A. Identifikasi Masalah}

Dalam langkah ini, dilakukan untuk mengetahui masalah yang ada dalam penelitian berdasarkan latar belakang penelitian sehingga dapat ditawarkan solusi untuk mengatasi masalah tersebut.

\section{B. Studi Literatur}

Studi literature adalah langkah yang dilakukan untuk mempelajari literatur berupa jurnal penelitian, paper, buku-buku referensi yang lain terkait dengan penelitian untuk melengkapi pengetahuan 
awal, guna memahami teori yang dapat digunakan untuk menunjang penelitian.

\section{Dataset}

Dataset yang digunakan adalah dataset wanita hamil yang diperoleh dari https://archive.ics.uci.edu/ml/datasets/Caes arian+Section+ Classification+ Dataset\#. Dataset ini mempunyai 80 record dengan 6 variabel yaitu: age(umur), delivery number (jumlah tenaga medis yang terlibat), delivery time (waktu melahirkan), blood of pressure (tekanan darah), heart problem (masalah jantung), dan Caesar.

\section{Data Preprocessing}

Sebelum data digunakan untuk tahapan klasifikasi, dataset dilakukan data prerpocessing yang nantinya meliputi : pembersihan data yang tidak lengkap (missing value), transformasi data, dan konversi data agar dapat digunakan pada tahap klasifikasi

\section{E. Klasifikasi}

Klasifikasi dilakukan dengan program aplikasi WEKA 3.6, merupakan perangkat lunak open source yang telah dikenal dan umum digunakan di bidang data mining dan machine learning. Pada WEKA 3.6 terdapat banyak tersedia library - library algoritma, baik untuk klasifikasi, clustering, association rule, bahkan sampai library untuk praproses data dan feature selection.

Klasifikasi nantinya akan menerapkan algoritma Naïve Bayes, dengan skenario uji dataset menggunakan pembagian persentase (percentage split), yaitu membagi jumlah keseluruhan data menjadi data training dan data testing. Adapun percentage split yang digunakan adalah: $5 \%, 15 \%, 25 \%, 35 \%, 45 \%, 55 \%, 65 \%$, $75 \%$, 85\%, dan 95\%. Percentage split 5\% artinya $5 \%$ data digunakan sebagai data training, dan $95 \%$ data digunakan sebagai data testing, demikian juga untuk percentage split yang lainnya. Hal ini dilakukan agar hasil yang diperoleh obyektif.

\section{F. Interpretasi dan Evaluasi}

Tahap ini merupakan tahap untuk menggali informasi berupa pengetahuan dari hasil klasifikasi yang selanjutnya dievaluasi apakah data yang diklasifikasikan sudah benar dengan menggunakan TP Rate, FP Rate, Precission dan Recall

\section{HASIL PENELITIAN}

Langkah awal adalah preprocessing data. Dataset yang digunakan adalah data ibu hamil yang nantinya akan dilakukan klasifikasi apakah melahirkan secara Caesar atau melahirkan secara normal.

\subsection{Preprocessing data}

Dataset dilakukan pembersihan data yang tidak lengkap (missing value), transformasi data, dan konversi data agar dapat digunakan pada tahap klasifikasi. Pada dataset ibu hamil ini, tidak terdapat missing value, outlier, maupun noise data. Dengan demikian, proses pembersihan data tidak perlu dilakukan. Selanjutnya, dilakukan transformasi dan konversi dataset.

Pada tahap transformasi dan konversi, format atau susunan data diubah menjadi format delimited, dengan pemisahnya adalah coma (,) dan menyimpan file ke dalam ekstensi coma separated value (csv). Tahap selanjutnya adalah konversi bentuk file ke dalam ekstensi (".arff) sehingga file dapat dipanggil dengan perangkat lunak WEKA.

Pada tahap ini, tahap preprocessing data selesai dilakukan, sehingga data dapat digunakan untuk tahap selanjutnya, yakni klasifikasi. 


\subsection{Klasifikasi}

Pada tahap ini, digunakan aplikasi WEKA 3.9 sebagai perangkat untuk membantu proses klasifikasi. Algoritma Naïve Bayes adalah algoritma yang digunakan di dalam penelitian ini. Dataset dibagi menjadi data training dan data testing menggunakan percentage split, sehingga diperoleh percentage split sebagai berikut: 5\%, 15\%, 25\%, 35\%, 45\%, $55 \%, 65 \%, 75 \%$, 85\%, dan 95\%. Hasil uji coba pada dataset dengan pembagian data menggunakan percentage split disajikan Tabel 1.

Tabel 1 memperlihatkan rincian persentase data terklasifikasi benar dan persetase data terklasifikasi salah. Nilai rata-rata data terklasifikasi benar adalah $67,16 \%$, sedangkan rata rata data terklasifikasi salah adalah $32,84 \%$. Adapun nilai tertinggi dan nilai terendah dari persentase data terklasifikasi benar masing-masing adalah $100 \%$ dan $55 \%$. Sedangkan nilai tertinggi dan terendah dari persentase data terklasifikasi salah masing-masing adalah $45 \%$ dan $0 \%$. Secara rata-rata, performa algoritma klasifikasi dengan algoritma Naïve Bayes masih kurang baik.

\begin{tabular}{|c|c|c|c|c|c|}
\hline No. & $\begin{array}{c}\text { Percen- } \\
\text { tage } \\
\text { Split }\end{array}$ & $\begin{array}{l}\text { Data } \\
\text { Trai- } \\
\text { ning } \\
\left(\sum\right)\end{array}$ & $\begin{array}{l}\text { Data } \\
\text { Tes- } \\
\text { ting } \\
\left(\sum\right)\end{array}$ & $\begin{array}{c}\text { Data } \\
\text { Terk- } \\
\text { lasifi- } \\
\text { kasi } \\
\text { Benar }\end{array}$ & $\begin{array}{c}\text { Data } \\
\text { Ter- } \\
\text { klasifi- } \\
\text {-kasi } \\
\text { Salah }\end{array}$ \\
\hline 1 & $5 \%$ & 4 & 76 & $57,89 \%$ & $42,1 \%$ \\
\hline 2 & $15 \%$ & 12 & 68 & $64,71 \%$ & $35,29 \%$ \\
\hline 3 & $25 \%$ & 20 & 60 & $61,67 \%$ & $38,33 \%$ \\
\hline 4 & $35 \%$ & 28 & 52 & $65,38 \%$ & $34,62 \%$ \\
\hline 5 & $45 \%$ & 36 & 44 & $68,18 \%$ & $31,82 \%$ \\
\hline 6 & $55 \%$ & 44 & 36 & $66,67 \%$ & $33,33 \%$ \\
\hline 7 & $65 \%$ & 52 & 28 & $57,14 \%$ & $42,86 \%$ \\
\hline 8 & $75 \%$ & 60 & 20 & $55 \%$ & $45 \%$ \\
\hline 9 & $85 \%$ & 68 & 12 & $75 \%$ & $25 \%$ \\
\hline 10 & $95 \%$ & 76 & 4 & $100 \%$ & $0 \%$ \\
\hline
\end{tabular}

Di samping hasil uji dari persentase data teklasifikasi benar dan persentase data terklasifikasi salah, kinerja algoritma Naïve Bayes untuk menglasifikasikan kelahiran ibu hamil secara normal ataukah
Caesar juga dilihat dari nilai precision dan recall. Pada penelitian ini data positif adalah data kelas melahirkan secara normal, sedangkan data negatif adalah data kelas melahirkan dengan Caesar. Nilai precision dan recall dapat dilihat pada Tabel 2.

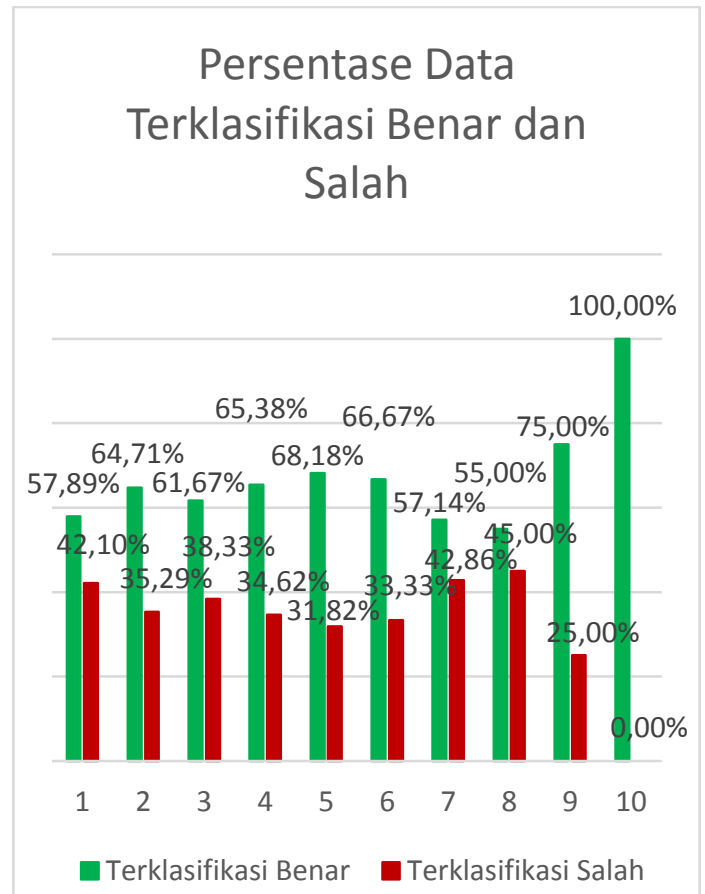

Tabel 2 Nilai TP Rate, FP Rate, Precision, dan Recall

\begin{tabular}{|c|c|c|c|c|c|c|c|}
\hline $\begin{array}{l}\mathrm{N} \\
\mathrm{o} \\
.\end{array}$ & $\begin{array}{l}\text { Perce } \\
\text { ntage } \\
\text { Split }\end{array}$ & $\begin{array}{c}\text { Data } \\
\text { Trai- } \\
\text { ning } \\
\left(\sum\right)\end{array}$ & $\begin{array}{c}\text { Data } \\
\text { Test } \\
\text {-ing } \\
\left(\sum\right)\end{array}$ & $\begin{array}{c}\text { TP } \\
\text { Ra } \\
\text { te }\end{array}$ & $\begin{array}{l}\text { FP } \\
\text { Ra } \\
\text { te }\end{array}$ & $\begin{array}{c}\text { Precis } \\
\text { sion }\end{array}$ & $\begin{array}{l}\mathrm{Re}- \\
\text { call }\end{array}$ \\
\hline 1 & $5 \%$ & 4 & 76 & $\begin{array}{c}0, \\
57 \\
9\end{array}$ & $\begin{array}{c}0, \\
36 \\
6\end{array}$ & 0,634 & $\begin{array}{c}0,57 \\
9\end{array}$ \\
\hline 2 & $15 \%$ & 12 & 68 & $\begin{array}{c}0, \\
64 \\
7\end{array}$ & $\begin{array}{l}0, \\
43\end{array}$ & 0,652 & $\begin{array}{c}0,64 \\
7\end{array}$ \\
\hline 3 & $25 \%$ & 20 & 60 & $\begin{array}{c}0, \\
61 \\
7\end{array}$ & $\begin{array}{c}0, \\
42 \\
2\end{array}$ & 0,611 & $\begin{array}{c}0,61 \\
7\end{array}$ \\
\hline 4 & $35 \%$ & 28 & 52 & $\begin{array}{c}0, \\
65 \\
4\end{array}$ & $\begin{array}{c}0, \\
33 \\
3\end{array}$ & 0,684 & $\begin{array}{c}0,65 \\
4\end{array}$ \\
\hline 5 & $45 \%$ & 36 & 44 & $\begin{array}{c}0, \\
68 \\
2\end{array}$ & $\begin{array}{c}0, \\
31 \\
6\end{array}$ & 0,704 & $\begin{array}{c}0,68 \\
2\end{array}$ \\
\hline 6 & $55 \%$ & 44 & 36 & $\begin{array}{c}0, \\
66 \\
7\end{array}$ & $\begin{array}{c}0, \\
36 \\
8\end{array}$ & 0,667 & $\begin{array}{c}0,66 \\
7\end{array}$ \\
\hline 7 & $65 \%$ & 52 & 28 & $\begin{array}{c}0, \\
57 \\
1\end{array}$ & $\begin{array}{c}0, \\
45 \\
3\end{array}$ & 0,568 & $\begin{array}{c}0,57 \\
1\end{array}$ \\
\hline 8 & $75 \%$ & 60 & 20 & 0 & 0 & 0,567 & 0,55 \\
\hline
\end{tabular}




\begin{tabular}{cccccccc} 
& & \multicolumn{8}{c}{55} & 45 & & \\
9 & $85 \%$ & 68 & 12 & 0, & 0, & & \\
& & & & 75 & 29 & 0,75 & 0,75 \\
1 & $95 \%$ & 76 & 4 & 1 & 0 & 1 & 1 \\
0 & & & & & \\
\hline
\end{tabular}

Berdasarkan Tabel 2, dapat dilihat nilai TP Rate, FP Rate, Precission dan Recall untuk masing-masing percentage split. Sehingga diperoleh nilai rata-rata $T P$ Rate sebesar 0,67, nilai rata-rata FP Rate sebesar 0,34, nilai rata-rata Precission sebesar 0,68 , dan nilai rata-rata Recall sebesar 0,67 . Berdasarkan nilai rata-rata Precission dan Recall dapat disimpulkan bahwa tingkat keefektifan klasifikasi dengan Naïve Bayes berada pada tingkat cukup baik. Nilai precission dan recall tertinggi berada pada hasil uji dataset dengan percentage split 95\%, yakni masing-masing bernilai 1 .

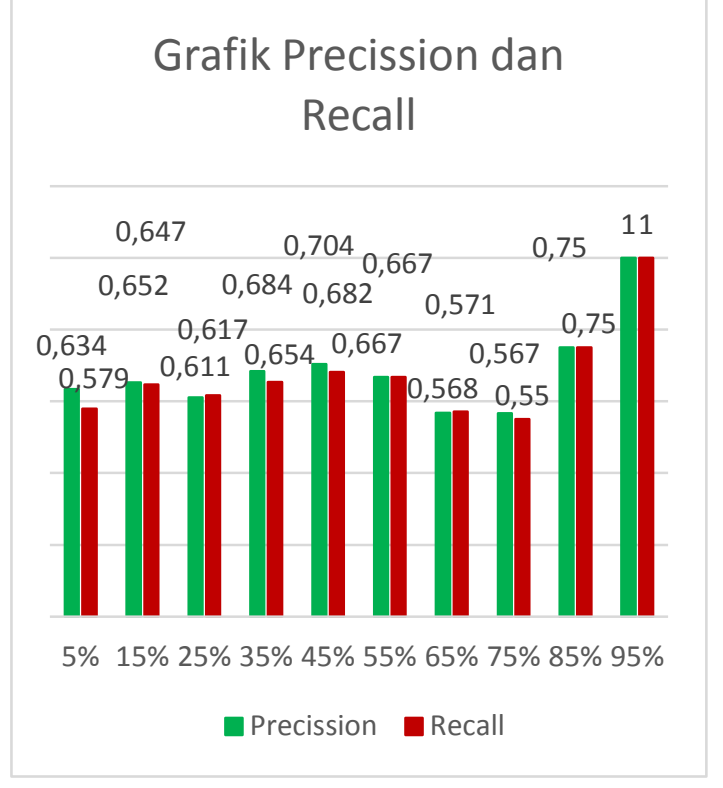

\section{KESIMPULAN}

Kesimpulan dalam penelitian ini yaitu klasifikasi kelahiran menggunakan algoritma Naïve Bayes masih menghasilkan nilai yang kurang baik. Hal ini ditunjukkan dari rata-rata terklasifikasi benar bernilai adalah $67,16 \%$, sedangkan rata rata data terklasifikasi salah adalah $32,84 \%$. Adapun nilai tertinggi dan nilai terendah dari persentase data terklasifikasi benar masing-masing adalah 100\% dan $55 \%$. Sedangkan nilai tertinggi dan terendah dari persentase data terklasifikasi salah masing-masing adalah $45 \%$ dan $0 \%$. Nilai precission dan recall tertinggi berada pada hasil uji dataset dengan percentage split 95\%, yakni masing-masing bernilai 1 . Saran untuk penelitian selanjutnya adalah menerapkan algoritma klasifikasi lain sebagai pembanding sehingga dapat meningkatkan performa klasifikasi

\section{DAFTAR PUSTAKA}

Andayasari, L., Muljati, S., Sihombing, M., Arlinda, D., Opitasari, C., Fajar, D., \& Widianto, M. (2015). Proporsi Seksio Sesarea dan Faktor yang Berhubungan dengan Seksio Sesarea di Jakarta THE PROPORTION OF CAESAREAN SECTION AND ASSOCIATED FACTORS IN HOSPITAL OF JAKARTA. Buletin Penelitian Kesehatan, 43(2), 105-116. https://doi.org/http://dx.doi.org/10.2243 5/bpk.v43i2.4144.105-116

Anggorowati, \& Sudiharjani, N. (2010). Mobilisasi Dini dan Penyembuhan Luka Operasi Pada Ibu Post Sectio Caesarea (SC) di Ruang Dahlia Rumah Sakit Umum Daerah Kota Salatiga. Prosiding Seminar Nasional Dan Internasional Universitas Muhammadiyah Semarang, 30-35.

Kemenkes. (2017). Profil Kesehatan Indonesia Tahun 2016. https://doi.org/10.1111/evo.12990

Lukman, A., \& Marwana. (2015). Machine Learning Multi Klasifikasi. Konferensi Nasional IImu Komputer (KONIK) 2014, (December 2014).

Sihombing, N., Saptarini, I., \& Putri, D. S. K. (2010). Determinan Persalinan Sectio Caesarea Di Indonesia (Analisis Lanjut Data Riskesdas 
2013). Jurnal Kesehatan Reproduksi,

8(1), 63-75.

https://doi.org/10.22435/kespro.v8i1.6

641.63-75 